\title{
Anastrozole as add-on therapy for cabergoline-resistant prolactin-secreting pituitary adenomas: real-life experience in male patients
}

\author{
Filippo Ceccato $^{1,2,3}$ (D) Laura Lizzul $^{1}$ (D) $\cdot$ Giacomo Voltan $^{1}$ (D) $\cdot$ Mattia Barbot $^{1,2}$ (D) $\cdot$ Carla Scaroni $^{1,2}$ (D)
}

Accepted: 17 June 2021 / Published online: 26 June 2021

(c) The Author(s) 2021

\begin{abstract}
Introduction Prolactin-secreting adenoma (PRLoma) can present as large and invasive neoplasm, with increased markers of cellular proliferation. First-line approach is Dopamine Agonists (DAs) treatment; however, DA-resistance has been reported, especially in male patients. Estrogens induce lactotroph cell replication and PRL secretion: the use of anti-estrogen treatment in patients with PRLoma have been described in few cases. We reported our experience regarding treatment with the aromatase inhibitor anastrozole (ANA) as add-on therapy for male patients with DA resistant PRLoma.

Materials and methods We describe four male patients (26, 38, 29 and 19 years old at diagnosis), with PRLoma (median diameter $26 \mathrm{~mm}$, PRL $7730 \mu \mathrm{g} / \mathrm{L}$ ). They were resistant to cabergoline (CAB, > $2 \mathrm{mg} / \mathrm{week})$ in terms of PRL secretion and tumor size reduction. ANA $1 \mathrm{mg} /$ day was added to the maximum tolerated dose of CAB for at least 1 year. Magnetic Resonance was performed at baseline, after 6 months of CAB + ANA combination and every 12 months afterward.

Results PRL levels decreased in all patients after CAB + ANA (mean - 70\%, range - 44/- 97\%), achieving a normalization of PRL levels in one case. Tumor size decreased in all cases (mean $-47 \%$, range $-24.5 /-68 \%$ ). No severe adverse effects have been reported, a moderate weight gain has been observed in two cases.

Conclusions Addition of an aromatase inhibitor (ANA) to the dopamine agonist therapy improved the control of prolactin levels and induced tumour regression.
\end{abstract}

Keywords Prolactin $\cdot$ Aggressive pituitary adenoma $\cdot$ Cabergoline $\cdot$ Anastrozole $\cdot$ Combined treatment

\section{Introduction}

Prolactin (PRL)-secreting adenomas (PRLomas) are the most common pituitary adenomas [1]. Usually, they present a benign clinical course and are responsive to dopamine agonist (DA) therapy, especially cabergoline (CAB),

Filippo Ceccato and Laura Lizzul should be considered jointly as first co-authors.

Filippo Ceccato

filippo.ceccato@unipd.it

1 Endocrinology Department of Medicine DIMED, University of Padova, Padova, Italy

2 Endocrine Disease Unit, European Reference Network On Rare Endocrine Conditions (endoERN) Center of Padova, University-Hospital of Padova, Padova, Italy

3 Department of Neuroscience DNS, University of Padova, Padova, Italy in terms of PRL secretion, recovery of gonadal function and size-reduction [2], in particular if PRL levels are $\leq 1 \mu \mathrm{g} / \mathrm{L}$ shorlty after treatment [3]. Some patients often achieve sustained remission even after DAs withdrawal [4, 5]. However, $10 \%$ of patients present DA-resistance $[6,7]$, defined as a failure to normalize PRL levels or to achieve $>50 \%$ of tumor size shrinkage [2]. In men, PRLomas are almost ten times less frequent than in females and they are more frequently macro-adenomas [2], with higher PRL levels (> $1000 \mu \mathrm{g} / \mathrm{L}$ ) [8], aggressive behaviour and DA-resistance $[9,10]$. Due to these aspects, in 2017 WHO classified PRLomas in men as a variant of aggressive pituitary adenomas [11]. In selected aggressive forms, resistant to high-dose DAs therapy, treatment is a challenge: the use of somatostatin analogs (octreotide [12] or pasireotide [13]), tyrosine kinase inhibitor (lapatinib, an oral epidermal growth factor receptor inhibitor [14]) or chemotherapy with alkylating agents (temozolomide [15]) has been recently proposed after surgery or radiotherapy failure. 
Whether gender differences reflect a delayed diagnosis or different cellular pathogenesis is poorly understood. The PRL synthesis and secretion is controlled by estrogens, thyrotropin-releasing hormone, epidermal growth factor, and dopamine [2]. The interplay between PRL and sex hormones is complex: estrogens induce lactotroph cell replication through pituitary tumor transforming gene (PTTG); antiestrogen treatment can revert it in ovariectomized rats, suggesting a role for selective anti-estrogen treatment in pituitary tumors $[16,17]$. A study by Munemura et al. showed that estrogens have a stimulatory effect on PRL secretion by uncoupling dopamine receptors from G-protein in rats [18]. In humans, similar findings were confirmed by the PRLoma growth during estrogen therapy in a transgender male-to-female patient [19]. Furthermore, testosterone could be aromatized to estradiol, giving male tumors an advantage on cell proliferation [20]. In men, a lower estrogen-receptor expression has been reported in aggressive PRLomas with DA-resistance [21].

To date, a few attempts with selective estrogen receptor modulators (SERMs) have been described, without promising results [22-24]. Aromatase inhibitors (ARIs) inhibit the transformation of testosterone to estradiol, and can have a role in lactotroph proliferation [25]. In 2002, a male patient with PRLoma treated with CAB showed a further PRL reduction with the association with the non-steroidal ARI anastrozole (ANA) [26]. Another case of ARI use (letrozole) was described more recently by Heidari et al., with comparable results [27].

Considering these isolated observations of combined therapy with ARIs and DAs playing a synergistic effect in males, we share our experience in 4 male patients treated with long-term $\mathrm{CAB}+\mathrm{ANA}$ therapy.

\section{Patients, materials and methods}

In our cohort of patients with PRLoma ( 94 females and 60 males, median follow-up 10 years, interquartile range: 6-14 years), four young males presented a macro/giant PRLoma, resistant to CAB medical therapy (> $2 \mathrm{mg} /$ week); clinical details are reported in Table 1.

At baseline and during follow-up, serum PRL levels were collected with a stress-free sampling in the early morning through an indwelling venous catheter; the upper limit of normality (ULN) in males is $15 \mu \mathrm{g} / \mathrm{L}$ (mean of at least 2 measurements).

A contrast-enhanced pituitary magnetic resonance (MR) was performed at least three times: at baseline, after 6 months of CAB therapy at its higher dose and after at least 6 months of combined therapy with ANA.

Each MR underwent an operator-independent quantitative assessment by two authors (F.C. and L.L.) performed with Horos [28], a free medical image viewer, to calculate the volume of the mass.

A Goldmann perimetry of visual field was performed at diagnosis and repeated if clinically necessary. All patients were screened for valvular heart disease with transthoracic color Doppler echocardiography (at baseline, then every 24-36 months or in case of a new-onset heart murmur). The hepatic and renal functions were normal in all patients before the initiation of $\mathrm{CAB}$ and $\mathrm{CAB}+\mathrm{ANA}$. After the written acquisition of informed consent, all patients were treated with off-label ANA $1 \mathrm{mg} /$ day in association with the maximum tolerated DAs dosage.

The cardio-metabolic profile was studied by systolic and diastolic blood pressure (SBP and DBP), heart rate (HR) and anthropometric measures at each visit, and biochemical blood sampling for fasting blood glucose, glycated

Table 1 Prolactin (PRL) levels and magnetic resonance (MR) size of pituitary tumors; $\Delta$ : percentual difference of PRLoma volume calculated between $\mathrm{CAB}$ alone (best diameter) and $\mathrm{CAB}+\mathrm{ANA}$ treatment

\begin{tabular}{|c|c|c|c|c|c|c|c|c|c|}
\hline $\begin{array}{l}\text { Patient, age } \\
\text { at PRLoma } \\
\text { diagnosis }\end{array}$ & $\begin{array}{l}\text { PRL }(\mu \mathrm{g} / \mathrm{L}) \\
\text { baseline }\end{array}$ & $\begin{array}{l}\text { MR baseline: Size } \\
(\mathrm{mm})-\text { Volume } \\
\left(\mathrm{mm}^{3}\right)\end{array}$ & $\begin{array}{l}\text { Nadir of PRL } \\
\text { level }(\mu \mathrm{g} / \mathrm{L}) \\
\text { during CAB }\end{array}$ & $\begin{array}{l}\text { Best MR size } \\
\text { achieved with } \\
\text { CAB: Size } \\
(\mathrm{mm})-\text { Volume } \\
\left(\mathrm{mm}^{3}\right)\end{array}$ & $\begin{array}{l}\text { Last CAB dose } \\
\text { prior to adding } \\
\text { ANA (mg/ } \\
\text { week) }\end{array}$ & $\begin{array}{l}\text { ANA treat- } \\
\text { ment (months) }\end{array}$ & $\begin{array}{l}\text { Nadir of PRL } \\
\text { level }(\mu \mathrm{g} / \mathrm{L}) \text { dur- } \\
\text { ing CAB + ANA; } \\
\Delta \text { reduction in } \\
\text { brackets }\end{array}$ & $\begin{array}{l}\text { Best } M R \text { size } \\
\text { achieved with } \\
\text { CAB+ANA: Size } \\
(\mathrm{mm})-\text { Volume } \\
\left(\mathrm{mm}^{3}\right) ; \Delta \text { volume } \\
\text { reduction in } \\
\text { brackets }\end{array}$ & $\begin{array}{l}\text { Last CAB } \\
\text { dose during } \\
\text { CAB }+A N A(\mathrm{mg} / \\
\text { week })\end{array}$ \\
\hline 1,26 years & 14.000 & $33 \times 23 \times 35-14,133$ & 1.920 & $\begin{array}{l}20 \times 19 \times 29- \\
5863\end{array}$ & 4.5 & 24 & $50(\Delta-97.4 \%)$ & $\begin{array}{c}15 \times 10 \times 23- \\
1835(\Delta \\
-68.7 \%)\end{array}$ & 3.5 \\
\hline 2,38 years & 33.000 & $52 \times 48 \times 50-65,573$ & 270 & $\begin{array}{c}35 \times 18 \times 12- \\
3972\end{array}$ & 4.5 & 56 & $23(\Delta-91.5 \%)$ & $\begin{array}{c}30 \times 17 \times 10 \\
-2681(\Delta \\
-32.5 \%)\end{array}$ & 4.5 \\
\hline 3,29 years & 1.460 & $17 \times 14 \times 15-1735$ & 35 & $13 \times 8 \times 10-506$ & 3 & 30 & $18(\Delta-48.6 \%)$ & $\begin{array}{r}11 \times 6 \times 6-193 \\
(\Delta-61.9 \%)\end{array}$ & 2 \\
\hline 4,19 years & 850 & $13 \times 15 \times 10-1091$ & 27 & $13 \times 5 \times 11-400$ & 3.5 & 15 & $14(\Delta-44 \%)$ & $\begin{array}{c}12 \times 5 \times 9-302 \\
(\Delta-24.5 \%)\end{array}$ & 3.5 \\
\hline
\end{tabular}


hemoglobin A1c (HbA1c), lipid profile at baseline, after at least 6 months of $\mathrm{CAB}$ at its higher dose and after $\mathrm{CAB}+\mathrm{ANA}$ association. Wearing light clothing and no shoes, participants were weighed and measured using a balanced beam scale and a vertical ruler. Weight was recorded to the nearest $0.5 \mathrm{~kg}$ and height to the nearest $0.5 \mathrm{~cm}$. In accordance with WHO guidelines, waist circumference was measured at the end of natural breaths at the midpoint between the top of the iliac crest and the lower margin of the last palpable rib. We considered hypertension if SBP levels were $\geq 130 \mathrm{mmHg}$ or $\mathrm{DBP} \geq 85 \mathrm{mmHg}$ (or if patients were receiving antihypertensive treatment). They were considered dyslipidemic if cholesterol or triglycerides were above normality (or being treated for dyslipidemia). The participants were considered diabetic if fasting plasma glucose was $\geq 5.5 \mathrm{mmol} / \mathrm{L}$ (or they were taking anti-diabetic drugs). BMD at lumbar spine (L1-L4) and femur (neck and total) was determined by DXA, using Hologic QDR 4500 C densitometer (Hologic Inc., Waltham, MA, USA).

Clinical data were collected in the web-based database of the University-Hospital of Padova, used as an electronic Case Report/Record Form (eCRF). The Ethics Committee of Padova University-Hospital approved the study.

\section{Results}

\section{Patient 1}

A 26-year-old man complained of palpebral ptosis, headache, and visual impairment with bitemporal hemianopsia. A pituitary MR revealed a large $(33 \times 41 \times 36 \mathrm{~mm})$ PRLoma with left cavernous sinus invasion. After 12 months of $\mathrm{CAB}$ treatment (up to $4.5 \mathrm{mg} /$ week), PRL levels were reduced, without a significant shrinkage of the tumor. The patient then underwent to microscope-assisted trans-nasal surgery (TNS). The histological finding was consistent with an atypical adenoma (according to the WHO classification in use) [29]: positive PRL staining in more than $80 \%$ of cells, increased mitotic figures, MIB-1 $>3 \%$, and positive p53. PRL levels did not improve after neurosurgery. After six years, he referred to our Endocrinology Unit, revealing persistently increased PRL levels $(2245 \mu \mathrm{g} / \mathrm{L})$ despite CAB treatment $(4.5 \mathrm{mg} /$ week $)$, with the persistence of a large residual adenoma. Central hypothyroidism and hypogonadotropic hypogonadism were adequately substituted with oral L-thyroxine and transdermal testosterone (see Table 2). PRL levels before and after testosterone treatment did not change. Genetic evaluation of menin and AIP gene resulted wild-type, and an oral glucose tolerance test excluded a concomitant GH secretion. High dose CAB therapy was poorly tolerated due to orthostatic hypotension; echocardiography excluded valvular defects. We associated ANA to a reduced

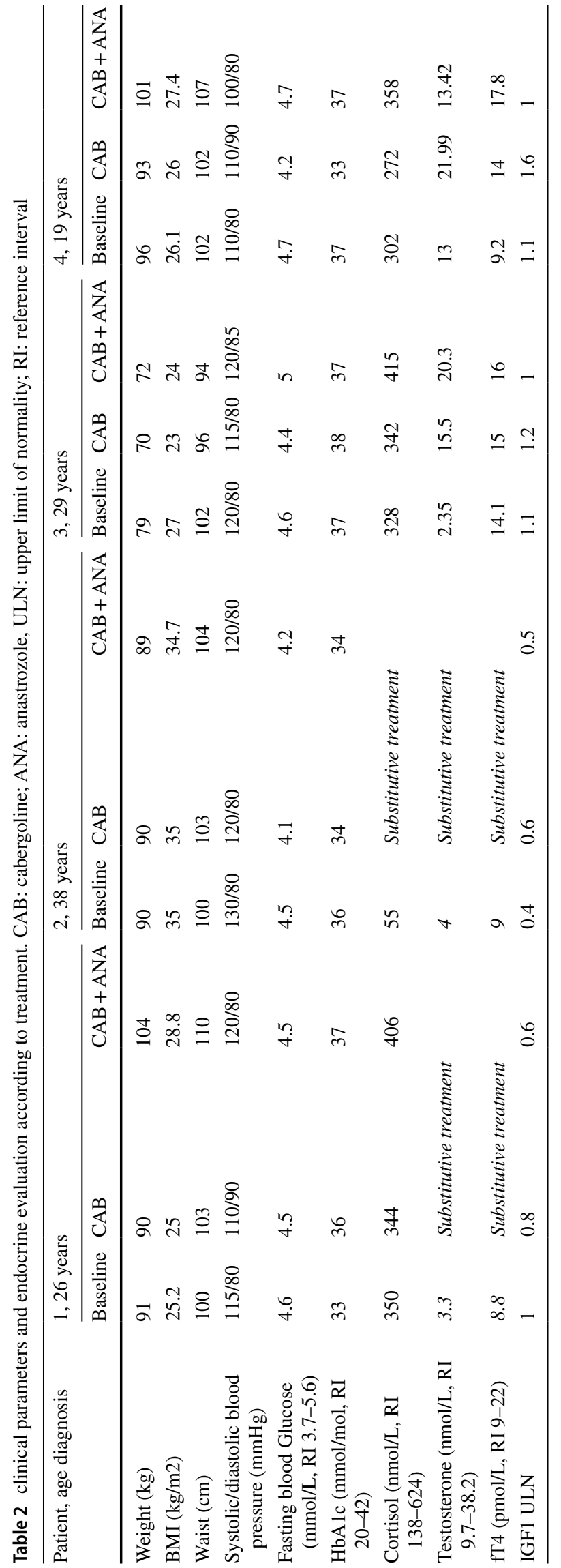


dose of CAB ( $3.5 \mathrm{mg} /$ week): the patient achieved a PRL leverel reduction $(145 \mu \mathrm{g} / \mathrm{L})$ in 3 months, with a nadir of $50 \mu \mathrm{g} / \mathrm{L}$, and a consistent shrinkage in tumor volume (see Fig. 1). After ANA initiation testosterone replacement therapy was maintained at the same dosage. ANA was well tolerated; a moderate increase of body weight was observed with combination treatment (detailed in Table 2).

\section{Patient 2}

A 38-year-old man complained of headache with diplopia and oculomotor nerve palsy; at Emergency the CT reported a giant invasive sellar mass $(60 \times 60 \times 72 \mathrm{~mm}$, with complete bilateral encasement of the cavernous sinus, showing lateral growth to the middle fossa and petrosal sinus). After surgical decompression (craniotomy approach), the patient developed anterior and posterior hypopituitarism; PRL levels before and after testosterone treatment did not show a significant change. Baseline PRL levels were extremely high $(55,440 \mu \mathrm{g} / \mathrm{L})$ and dropped only partially after surgery $(33,000 \mu \mathrm{g} / \mathrm{L})$, with a large residual adenoma $(52 \times 48 \times 50 \mathrm{~mm})$. The patient received CAB (up to $5 \mathrm{mg} /$ week), with partial control of PRL levels $(270 \mu \mathrm{g} / \mathrm{L})$.

A 12-months combined treatment with octreotide longacting release (LAR, $30 \mathrm{mg}$ monthly), achieved a nadir in PRL level $(100 \mu \mathrm{g} / \mathrm{L})$ and a partial response in tumor size $(30 \times 18 \times 12 \mathrm{~mm})$. Somatostatin analog was discontinued for a progressive increase of liver enzymes, measured every 4 weeks: alanine transaminase $48 \quad 139 \quad 178 \quad 74 \quad 44$ U/L (range 10-50), aspartate transaminase $\begin{array}{llll}30 & 67 & 80 & 42\end{array}$ $33 \mathrm{U} / \mathrm{L}$ (range 10-45), $\gamma$-glutamyltransferase $47 \quad 170158$ $10161 \mathrm{U} / \mathrm{L}$ (range 3-65). This adverse event (grade 2 in the Common Terminology Criteria for Adverse Events Version 5.0) was asymptomatic, an abdominal ultrasound excluded gallbladder sludge and stones, and recovered after octreotide discontinuation. The rebound of PRL levels $(930 \mu \mathrm{g} / \mathrm{L})$ pushed us to start the association with CAB (4.5 mg/week) + ANA, resulting in a nadir of PRL levels of $23 \mu \mathrm{g} / \mathrm{L}$ and in a further size reduction of the pituitary adenoma.

Subsequent attempts to reduce the CAB dose led to a PRL escape, with good tolerability profile and absence of valvular defects. After ANA initiation the replacement therapy with $50 \mathrm{mg} /$ day of transdermal testosterone was maintained. ANA was well tolerated; a progressive rise in bone turnover markers was observed, a dorsal spine radiography excluded vertebral fractures.

\section{Patient 3}

A 29-year-old man suffering from migraine performed a cerebral MR with the incidental detection of pituitary adenoma $(17 \times 14 \times 15 \mathrm{~mm}$, with bilateral cavernous sinus invasion and PRL $1460 \mu \mathrm{g} / \mathrm{L}$ ); he also reported decreased libido and erectile dysfunction for two years. The genetic evaluation of AIP and menin gene mutations indicated wild-type genotype, an oral glucose tolerance test excluded an autonomous GH secretion; a hypogonadotropic hypogonadism was observed. A significant reduction of PRL levels (up to $35 \mu \mathrm{g} / \mathrm{L}$ ) was achieved with CAB $3 \mathrm{mg} / \mathrm{week}$, with the restoration of the normal gonadal function, without a consistent shrinkage of the pituitary lesion and with a poor dose tolerance due to hypotension and paroxysmal palpitations. The color-doppler echocardiography excluded valvular heart disease. The patient refused TNS. Therefore, to reduce drug-related side-effects, we started $\mathrm{CAB}+\mathrm{ANA}$ with step reductions in $\mathrm{CAB}$ dose to $2 \mathrm{mg} /$ week (-0.5 mg after 6 and 12 months), achieving a further reduction of PRL nadir to $18 \mu \mathrm{g} / \mathrm{L}$, a shrinkage of the pituitary adenoma (up to $11 \times 6 \times 6 \mathrm{~mm}$ ) and a better tolerance of CAB.
Fig. 1 Tumor volume at baseline, after Cabergoline $(\mathrm{CAB})$ and after combined Cabergoline + Anastrozole (CAB + ANA) treatment. Patient's number is the same reported in Table 1. Tumor volume is depicted in logharitmic base 10 scale

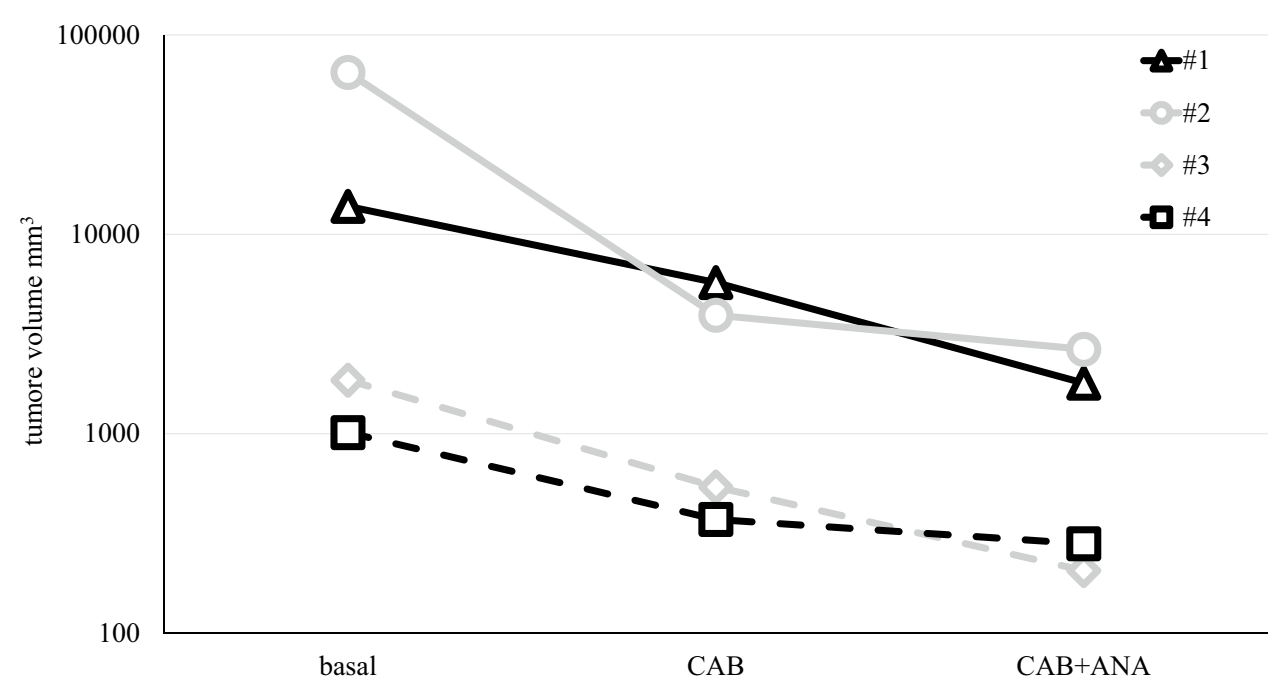




\section{Patient 4}

A 19-year-old boy, after a head trauma, performed MR with the incidental finding of a pituitary adenoma $(13 \times 15 \times 10 \mathrm{~mm}$, PRL $850 \mu \mathrm{g} / \mathrm{L})$. The genetic evaluation of AIP and menin gene mutations indicated a wild-type genotype, an oral glucose tolerance test excluded an autonomous GH secretion, the remaining pituitary function was normal. We started $\mathrm{CAB}$ at $1 \mathrm{mg} /$ week with a further progressive increase to $3.5 \mathrm{mg} /$ week reaching only a sub-normalization of PRL secretion $(27 \mu \mathrm{g} / \mathrm{L})$ with an absent control of the pituitary adenoma size $(13 \times 5 \times 11 \mathrm{~mm})$. The patient refused neurosurgery; therefore, ANA $1 \mathrm{mg} /$ day was added, achieving the normalization of the PRL levels and a reduction of the pituitary adenoma within the first 6 months of association therapy. No side effects have been reported, except a slight increase in body weight.

\section{Discussion}

The treatment of patients with DA-resistant PRLoma is troublesome. In general DA treatment is recommended as the mainstay therapy, achieving biochemical remission in up to $80 \%$ of patients [30]. Neurosurgery is suggested not only in aggressive or large tumors, but also in non-invasive adenomas, for its capacity to achieve a sustained remission [31]. However, complications after pituitary surgery (hypopituitarism, infections, and cerebrospinal fluid leakage) can limit its indication [31], and in some cases, total removal of the adenoma cannot be performed, especially if the cavernous sinus is invaded.

Several definitions have been proposed to describe DAs resistance, one of the widely accepted is a failure to normalize PRL levels and to reduce tumor volume (at least 50\%) with $2 \mathrm{mg} /$ week of CAB [32]. In this setting, the most frequent clinical management is to offer TNS or to increase the dose of DA if tolerated.

The first report of a young male patient with DAsresistant giant PRLoma treated with ANA was published in 2000. After the initial use of bromocriptine (with a consistent result on PRL secretion without adenoma shrinkage) $\mathrm{CAB}$ was initiated and increased up to $21 \mathrm{mg} /$ week, achieving partial endocrine control. Since hypogonadism did not recover after PRL reduction, 3 attempts of testosterone substitutive treatment were done, observing a rise in PRL levels. Therefore, a selective ARI (ANA, $1 \mathrm{mg}$ / day) was started and prolonged for 54 months achieving a decrease in PRL levels and a progressive reduction of CAB dose (to $5.5 \mathrm{mg} /$ week) [26]. Afterwards, another case report was published, describing letrozole $(2.5 \mathrm{mg} /$ day $)$ used as add-on therapy to bromocriptine and testosterone + hCG in a 36-years old man with a resistant PRLoma, with central hypogonadism and infertility. After 32 months of combination therapy, PRL decreased up to $75 \%$ and the sperm count improved leading to a spontaneous pregnancy [27]. This evidence pushed us to offer a combined approach with $\mathrm{CAB}$ and ANA in selected male patients with macro/giant PRLomas resistant to DA therapy, after unsuccessful or refused neurosurgery.

We report our experience with 4 patients, treated with combined CAB (maximum tolerated dose) $+1 \mathrm{mg}$ ANA for at least one year. In our series, we observed a wide range of responses to $\mathrm{CAB}+\mathrm{ANA}$ (from $-44 \%$ to- $97 \%$ in terms of PRL secretion, mean -70\%); one patient achieved a complete normalization of PRL levels. Regarding previously published case reports, a normalization of PRL levels was not reported [26, 27]. Considering tumor volume, a mean shrinkage of $47 \%$ was observed (range of reduction from $-25 \%$ to $-69 \%)$. In patients with other pituitary adenomas (such as those GH-secreting [33]), at least $\geq 20 \%$ of tumor volume reduction is considered an effective endpoint. Given that the typical reduction of PRL secreting macro-adenoma with $\mathrm{CAB}$ is usually close to $60 \%$ in DA-sensitive forms [34], our experience shows promising results and could pave the way for a prospective study in DA-resistant patients. In our series we did not observe a complete resistance to CAB; nevertheless, in all cases, the highest tolerated doses of $\mathrm{CAB}$ (ranging from 3 to $5 \mathrm{mg} /$ week) were able to achieve only a sub-normalization of PRL levels and a mild reduction of tumor burden. ANA association let a CAB dose reduction $(1 \mathrm{mg} /$ week) in two cases (patient \#1 started with a lower dose, patient \#2 reduced dose in the follow up) and increased adherence to treatment. Large and aggressive PRLomas present a male:female ratio of 9:1 [8], therefore our combined treatment could be considered at least in those adenomas with reduced likelihood of surgical remission.

It has been previously reported in the first case report that testosterone replacement therapy can promote a rise in PRL levels or adenoma growth (via the aromatization to estradiol) [26]. Patients \#1 and \#2 presented a central hypogonadism (secondary to surgery and elevated PRL levels); their testosterone levels were kept at the lower limit of the normal range with a transdermal dose sufficient to restore sexual function. Testosterone levels in patient \#3 were normal after PRL reduction, as expected. Recently, it has been reported that ARIs can be used as an off-label treatment in patients with central hypogonadism, especially if testosterone could not be considered as replacement therapy (fertility preservation, prostate cancer, polycythemia, thrombophilia and severe cardiovascular disease) [35]. However, we did not observe a significant rise in androgen levels after ANA treatment, neither in eugonadal patients nor in the 2 patients with post-surgical hypogonadotropic hypogonadism (treated with transdermal testosterone). Replacement doses of testosterone were not modified during $\mathrm{CAB}+\mathrm{ANA}$ therapy. 
Gonadotropin levels in the two eugonadal patients did not show significant changes after ANA.

In our series, high-dose $\mathrm{CAB}$ treatment (at least $>2 \mathrm{mg}$ / week) was a selection criteria, therefore DAs-related sideeffects are a matter of concern. Postural hypotension is not uncommon in ergot-based DA [36], and limited the use of high-doses $\mathrm{CAB}$ in 2 out of 4 patients. We did not observe any new-onset cardiac valvulopathy (an increased prevalence of tricuspid regurgitation has been reported with $\mathrm{CAB}$, mediated by $5 \mathrm{HT}_{2 \mathrm{~B}}$ receptors [37]) or impulsive control disorders and hypersexuality (that are more common in males, especially if current smokers or with high testosterone levels [38]). ANA was well tolerated, with no appearance of common acute side effects (such as nausea, headache, arthralgia, alteration of liver function markers) [39]. Pituitary function was assessed at baseline, during $\mathrm{CAB}$ treatment and after $\mathrm{CAB}+\mathrm{ANA}$ association. We did not observe new-onset hypopituitarism or a modification in the substitutive treatment. In our series, we did not observe a change in SBP, DBP and HT after the ANA combination. In two patients (\#1 and \#4) we registered a sensible weight gain with the rise of body mass index (BMI) and enlargement of waist circumference after ANA. The fasting blood glucose and Hb1 Ac levels maintained normal throughout the entire follow-up in all patients. The lipid profile did not show a consistent modification during the study. We study $\mathrm{CAB}+\mathrm{ANA}$ association only in males; nonetheless, ARI are used also to treat estrogen receptor-positive breast cancer post-menopausal females, with a well-known safety profile: arthralgia, muscle pain and stiffness, reduction in lean body mass, mood swings, decrease in cognition and executive functioning, hot flashes, and night sweats [40]. Although aggressive PRLomas are more common in males, the combination of DAs and ARIs should be considered also in postmenopausal females.

Surgical management of PRLomas is effective in microadenomas or intra-sellar macroadenomas: remission-rate is elevated when the TNS procedure is performed by highvolume surgeons, and may be a cost-effective option in young patients $[8,41]$. In case of large or invasive adenomas, postoperative symptoms-mass or increased PRL levels arises from tumor remnants: high-dose $\mathrm{CAB}$ treatment is required, with increased risk of side-effects [37, 42]. In our case-series, we described two different type of patients: \#1 and \#2 presented with with large and invasive PRLoma after surgical failure, requiring alternative therapeutic strategy for disease control and achieving a significant result (in terms of size and PRL secretion). On the other hand, patient \#3 and \#4 had smaller and less invasive lesions, and presented PRL levels close-to-normal with $\mathrm{CAB}$. They both refused TNS, and CAB was not tolerated in one case. The therapeutic decision is a challenge in such cases, and in our opinion an effort to discuss these cases in a Multidisciplinary
Team in a Pituitary Tumors Center of Excellence should be empowered [43].

Estrogens are essential for mineral metabolism and bone health in males. Estrogen determines the acceleration of bone elongation at puberty and epiphyseal closure, the achievement of skeletal proportions and peak bone mass, the maintenance of bone mass during adulthood and crosstalk with androgen for bone mass maintenance via the modulation of formation and resorption [44, 45]. In our study, we do not observe a negative impact of ARI treatment on bone quality and metabolism. We observed in patient \#2 a progressive rise of bone resorbtion markers since ANA was initiated, a dorsal spine X-ray excluded vertebral collapses and the DXA scan showed osteopenia. In this particular situation, we must also bear in mind the concomitant presence of hydrocortisone replacement therapy $(20 \mathrm{mg} /$ day $)$ and the untreated GH deficiency as concomitant factors for bone damage. The remaining 3 patients did not show any impairment of bone metabolism: further studies with larger cohorts are needed to study the impact of long-term ARI treatment on fracture risk.

CAB can be used in monotherapy or associated with somatostatin analogs in acromegalic patients: it is a low-cost oral treatment, effective in selected cases; however, there is a paucity of evidence regarding its efficacy [46, 47]. In our cohort, the addition of octreotide LAR to CAB resulted in a significant response in terms of PRL levels and adenoma size, as recently reported [12]; however, the development of liver function abnormalities resulted in somatostatin analog discontinuation. Estrogens antagonize GH receptor function, reducing hepatic IGF-1 synthesis: oral, but not transdermal, estrogen administration lowers circulating IGF-I [48]. The IGF-I suppression observed by the selective estrogen receptor modulators tamoxifen and raloxifen seems to correspond to those observed with oral estrogens: a randomized openlabel study in 2018 reported that raloxifene could decrease serum IGF-1 level in acromegaly [49]. At the best of our knowledge, the use of ARI (alone or combined with CAB) is not reported in acromegaly, and should be considered in selected patients.

We are aware of the several limitations of this work. First, the observational and spontaneous design without a control group. Then, the small and heterogeneous cohort, with hypopituitarism acting as a confounding factors.

To conclude, we described an effective associationtherapy with CAB and ANA. This option can lead to better control of PRL levels and to the shrinkage of tumor size, without serious adverse events. Its use should be considered for males or post-menopausal females with PRLomas, resistant to DAs, not a candidate or not willing a neurosurgical approach, especially when there is a high risk of iatrogenic hypopituitarism. 
Authors' contributions All authors contributed equally to the study design, to data acquisition, analysis, and interpretation, and to the drafting of the manuscript. They all approved the final version of the paper. Research involving human participants and patient consent: Informed consent was obtained from all participants.

Funding Open access funding provided by Università degli Studi di Padova within the CRUI-CARE Agreement. This study did not receive any specific grant from any funding agency in the public, commercial or not-for-profit sector.

Data availability All data generated or analyzed during this study are included in this article.

\section{Declarations}

Conflict of interest All authors declare that they have no conflicts of interest that might be perceived as influencing the impartiality of the reported research.

Open Access This article is licensed under a Creative Commons Attribution 4.0 International License, which permits use, sharing, adaptation, distribution and reproduction in any medium or format, as long as you give appropriate credit to the original author(s) and the source, provide a link to the Creative Commons licence, and indicate if changes were made. The images or other third party material in this article are included in the article's Creative Commons licence, unless indicated otherwise in a credit line to the material. If material is not included in the article's Creative Commons licence and your intended use is not permitted by statutory regulation or exceeds the permitted use, you will need to obtain permission directly from the copyright holder. To view a copy of this licence, visit http://creativecommons.org/licenses/by/4.0/.

\section{References}

1. Daly AF, Rixhon M, Adam C, Dempegioti A, Tichomirowa MA, Beckers A (2006) High prevalence of pituitary adenomas: a cross-sectional study in the province of Liège. Belgium J Clin Endocrinol Metab 91(12):4769-4775. https://doi.org/10.1210/jc. 2006-1668

2. Melmed S, Casanueva FF, Hoffman AR et al (2011) Diagnosis and treatment of hyperprolactinemia: an Endocrine Society clinical practice guideline. J Clin Endocrinol Metab 96(2):273-288. https://doi.org/10.1210/jc.2010-1692

3. Kim D, Ku CR, Kim K, Jung H, Lee EJ (2020) Prolactin $\leq 1$ $\mathrm{ng} / \mathrm{mL}$ predicts macroprolactinoma reduction after cabergoline therapy. Eur J Endocrinol 182(2):177-183. https://doi.org/10. 1530/EJE-19-0753

4. Sala E, Bellaviti Buttoni P, Malchiodi E et al (2016) Recurrence of hyperprolactinemia following dopamine agonist withdrawal and possible predictive factors of recurrence in prolactinomas. J Endocrinol Invest 39(12):1377-1382. https://doi.org/10.1007/ s40618-016-0483-z

5. Watanabe S, Akutsu H, Takano S et al (2017) Long-term results of cabergoline therapy for macroprolactinomas and analyses of factors associated with remission after withdrawal. Clin Endocrinol (Oxf) 86(2):207-213. https://doi.org/10.1111/cen.13240

6. Ono M, Miki N, Kawamata T et al (2008) Prospective study of high-dose cabergoline treatment of prolactinomas in 150 patients. J Clin Endocrinol Metab 93(12):4721-4727. https://doi.org/10. 1210/jc.2007-2758
7. Souteiro P, Karavitaki N (2020) Dopamine agonist resistant prolactinomas: any alternative medical treatment? Pituitary 23(1):2737. https://doi.org/10.1007/s11102-019-00987-3

8. Melmed S (2020) Pituitary-Tumor Endocrinopathies. N Engl J Med 382(10):937-950. https://doi.org/10.1056/NEJMra1810772

9. Delgrange E, Daems T, Verhelst J, Abs R, Maiter D (2009) Characterization of resistance to the prolactin-lowering effects of cabergoline in macroprolactinomas: a study in 122 patients. Eur $\mathrm{J}$ Endocrinol 160(5):747-752. https://doi.org/10.1530/EJE-09-0012

10. Colao A, Vitale G, Cappabianca P et al (2004) Outcome of cabergoline treatment in men with prolactinoma: effects of a 24-month treatment on prolactin levels, tumor mass, recovery of pituitary function, and semen analysis. J Clin Endocrinol Metab 89(4):1704-1711. https://doi.org/10.1210/jc.2003-030979

11. Lopes MBS (2017) The 2017 World Health Organization classification of tumors of the pituitary gland: a summary. Acta Neuropathol 134(4):521-535. https://doi.org/10.1007/ s00401-017-1769-8

12. Sosa-Eroza E, Espinosa E, Ramírez-Rentería C, Mendoza V, Arreola R, Mercado M (2018) Treatment of multiresistant prolactinomas with a combination of cabergoline and octreotide LAR. Endocrine 61(2):343-348. https://doi.org/10.1007/s12020-018-1638-9

13. Raverot G, Vasiljevic A, Jouanneau E, Lasolle H (2019) Confirmation of a new therapeutic option for aggressive or dopamine agonist-resistant prolactin pituitary neuroendocrine tumors. Eur J Endocrinol 181(2):C1-C3. https://doi.org/10.1530/EJE-19-0359

14. Cooper O, Bonert VS, Rudnick J et al (2021) EGFR/ErbB2targeting lapatinib therapy for aggressive prolactinomas. J Clin Endocrinol Metab 106(2):e917-e925. https://doi.org/10.1210/ clinem/dgaa805

15. Ceccato F, Lombardi G, Albiger N et al (2019) Temozolomide cytoreductive treatment in a giant cabergoline-resistant prolactin-secreting pituitary neuroendocrine tumor. Anticancer Drugs 30(5):533-536. https://doi.org/10.1097/CAD.0000000000000768

16. Heaney AP, Fernando M, Melmed S (2002) Functional role of estrogen in pituitary tumor pathogenesis. J Clin Invest 109(2):277-283. https://doi.org/10.1172/JCI14264

17. Sosic Jurjevic B, Ajdzanovic V, Miljic D, et al. 2020 Pituitary Hyperplasia, Hormonal Changes and Prolactinoma Development in Males Exposed to Estrogens An Insight From Translational Studies. Int J Mol Sci Doi: https://doi.org/10.3390/ijms21062024

18. Munemura M, Agui T, Sibley DR (1989) Chronic estrogen treatment promotes a functional uncoupling of the D2 dopamine receptor in rat anterior pituitary gland. Endocrinology 124(1):346-355. https://doi.org/10.1210/endo-124-1-346

19. García-Malpartida K, Martín-Gorgojo A, Rocha M, Gómez-Balaguer M, Hernández-Mijares A (2010) Prolactinoma induced by estrogen and cyproterone acetate in a male-to-female transsexual. Fertil Steril 94(3):1097.e13-1097.e15. https://doi.org/10.1016/j. fertnstert.2010.01.076

20. Fainstein Day P, Glerean M, Lovazzano S et al (2010) Gender differences in macroprolactinomas: study of clinical features, outcome of patients and ki-67 expression in tumor tissue. Front Horm Res 38:50-58. https://doi.org/10.1159/000318494

21. Delgrange E, Vasiljevic A, Wierinckx A et al (2015) Expression of estrogen receptor alpha is associated with prolactin pituitary tumor prognosis and supports the sex-related difference in tumor growth. Eur J Endocrinol 172(6):791-801. https://doi.org/10. 1530/EJE-14-0990

22. Volker W, Gehring WG, Berning R, Schmidt RC, Schneider J, Mühlenvon zur A (1982) Impaired pituitary response to bromocriptine suppression: reversal after bromocriptine plus tamoxifen. Acta Endocrinol (Copenh) 101(4):491-500

23. Lamberts SWJ, Verleun T, Oosterom R (1982) Effect of tamoxifen administration on prolactin release by invasive prolactin-secreting 
pituitary adenomas. Neuroendocrinology 34(5):339-342. https:// doi.org/10.1159/000123324

24. Choudhary C, Hamrahian AH, Bena JF, Recinos P, Kennedy L, Dobri G (2019) The effect of raloxifene on serum prolactin level in patients with prolactinoma. Endocr Pract 25(7):684-688. https://doi.org/10.4158/EP-2018-0321

25. García-Barrado MJ, Blanco EJ, Iglesias-Osma MC et al (2017) Relation among aromatase P450 and tumoral growth in human prolactinomas. Int J Mol Sci 18(11):1-16. https://doi.org/10.3390/ ijms 18112299

26. Gillam MP, Middler S, Freed DJ, Molitch ME (2002) The novel use of very high doses of cabergoline and a combination of testosterone and an aromatase inhibitor in the treatment of a giant prolactinoma. J Clin Endocrinol Metab 87(10):4447-4451. https:// doi.org/10.1210/jc.2002-020426

27. Heidari Z, Hosseinpanah F, Shirazian N (2010) Achievement of fertility in an infertile man with resistant macroprolactinoma using high-dose bromocriptine and a combination of human chorionic gonadotropin and an aromatase inhibitor. Endocr Pract 16(4):669672. https://doi.org/10.4158/EP10026.CR

28. Horos - DICOM software. https://horosproject.org/downl oad-horos/.

29. DeLellis R. Pathology and Genetics of Tumours of Endocrine Organs. (WHO classification of tumors, ed.). IARC Press Lyon; 2004.

30. Varlamov EV, McCartney S, Fleseriu M (2019) Functioning pituitary adenomas - current treatment options and emerging medical therapies. Eur Endocrinol 15(1):30-40. https://doi.org/10.17925/ EE.2019.15.1.30

31. Zamanipoor Najafabadi AH, Zandbergen IM, de Vries F et al (2019) Surgery as a viable alternative first-line treatment for prolactinoma patients a systematic review and meta-analysis. J Clin Endocrinol Metab 105(3):1-10. https://doi.org/10.1210/clinem/ dgz144

32. Vilar L, Abucham J, Albuquerque JL et al (2018) Controversial issues in the management of hyperprolactinemia and prolactinomas - An overview by the neuroendocrinology department of the brazilian society of endocrinology and metabolism. Arch Endocrinol Metab. 62(2):236-263. https://doi.org/10.20945/23593997000000032

33. Caron PJ, Bevan JS, Petersenn S et al (2014) Tumor shrinkage with lanreotide autogel $120 \mathrm{mg}$ as primary therapy in acromegaly: results of a prospective multicenter clinical trial. J Clin Endocrinol Metab 99(4):1282-1290. https://doi.org/10.1210/jc.2013-3318

34. Colao A (2000) Macroprolactinoma shrinkage during cabergoline treatment is greater in naive patients than in patients pretreated with other dopamine agonists: a prospective study in 110 patients. J Clin Endocrinol Metab 85(6):2247-2252. https://doi.org/10. 1210/jc.85.6.2247

35. Ide V, Vanderschueren D, Antonio L (2021) Treatment of men with central hypogonadism: Alternatives for testosterone replacement therapy. Int J Mol Sci 22(1):1-13. https://doi.org/10.3390/ ijms 22010021

36. Hollingworth SA, McGuire TM, Pache D, Eadie MJ (2015) Dopamine agonists: time pattern of adverse effects reporting in Australia. Drugs - Real World Outcomes 2(3):199-203. https://doi. org/10.1007/s40801-015-0028-3
37. Stiles CE, Tetteh-Wayoe ET, Bestwick J, Steeds RP, Drake WM (2018) A meta-analysis of the prevalence of cardiac valvulopathy in hyperprolactinemic patients treated with Cabergoline. J Clin Endocrinol Metab. https://doi.org/10.1210/jc.2018-01071

38. Dogansen SC, Cikrikcili U, Oruk G et al (2019) Dopamine agonist-induced impulse control disorders in patients with prolactinoma: a cross-sectional multicenter study. J Clin Endocrinol Metab 104(7):2527-2534. https://doi.org/10.1210/jc.2018-02202

39. Plourde PV, Dyroff M, Dukes M (1994) Arimidex@: a potent and selective fourth-generation aromatase inhibitor. Breast Cancer Res Treat 30(1):103-111. https://doi.org/10.1007/BF00682745

40. Raptopoulos Z, Constantinou C (2020) The effect of exercise on the alleviation of side effects induced by aromatase inhibitors in postmenopausal breast cancer patients. Curr Oncol Rep 22(11):110. https://doi.org/10.1007/s11912-020-00971-2

41. Tampourlou M, Trifanescu R, Paluzzi A, Ahmed SK, Karavitaki N (2016) THERAPY OF ENDOCRINE DISEASE: surgery in microprolactinomas: effectiveness and risks based on contemporary literature. Eur J Endocrinol 175(3):R89-R96. https://doi.org/ 10.1530/EJE-16-0087

42. Beccuti G, Guaraldi F, Natta G et al (2020) Increased prevalence of impulse control disorder symptoms in endocrine diseases treated with dopamine agonists: a cross-sectional study. J Endocrinol Invest. https://doi.org/10.1007/s40618-020-01478-0

43. Casanueva FF, Barkan AL, Buchfelder M et al (2017) Criteria for the definition of pituitary tumor centers of excellence (PTCOE): a pituitary society statement. Pituitary 20(5):489-498. https://doi. org/10.1007/s11102-017-0838-2

44. Rochira V, Kara E, Carani C (2015) The endocrine role of estrogens on human male skeleton. Int J Endocrinol 2015:165215. https://doi.org/10.1155/2015/165215

45. Burnett-Bowie SAM, McKay EA, Lee H, Leder BZ (2009) Effects of aromatase inhibition on bone mineral density and bone turnover in older men with low testosterone levels. J Clin Endocrinol Metab 94(12):4785-4792. https://doi.org/10.1210/jc.2009-0739

46. Marazuela M, Ramos-Leví A, Sampedro-Núñez M, Bernabeu I (2014) Cabergoline treatment in acromegaly: pros. Endocrine 46(2):215-219. https://doi.org/10.1007/s12020-014-0206-1

47. Kasuki L, Vieira Neto L, Gadelha MR (2014) Cabergoline treatment in acromegaly: cons. Endocrine 46(2):220-225. https://doi. org/10.1007/s12020-014-0183-4

48. Jallad RS, Bronstein MD (2013) The place of medical treatment of acromegaly: current status and perspectives. Expert Opin Pharmacother 14(8):1001-1015. https://doi.org/10.1517/14656566.2013. 784744

49. Imani M, Khamseh ME, Asadi P et al (2018) Comparison of cabergoline versus raloxifene add-on therapy to long-acting somatostatin analogue in patients with inadequately controlled acromegaly: a randomized open label clinical trial. Endocr Pract 24(6):542-547. https://doi.org/10.4158/EP-2017-0195

Publisher's Note Springer Nature remains neutral with regard to jurisdictional claims in published maps and institutional affiliations. 